\title{
Correction to: Selective Cadmium Fluorescence Probe Based on Bis-Heterocyclic Molecule and its Imaging in Cells
}

\author{
Masayori Hagimori $^{1,2} \cdot$ Yasushi Karimine $^{2} \cdot$ Naoko Mizuyama $^{3} \cdot$ Fumiko Hara $^{1} \cdot$ Takeshi Fujino $^{4} \cdot$ Hideo Saji $^{5}$. \\ Takahiro Mukai ${ }^{6}$
}

Published online: 22 February 2022

(C) Springer Science+Business Media, LLC, part of Springer Nature 2022

\section{Correction to: Journal of Fluorescence.} https://doi.org/10.1007/s10895-021-02748-7

The original version of this article unfortunately contained a mistake. The equation under "Experimental - Spectroscopic Studies" section should be corrected as per the following. The original article has been corrected.

$1 /\left(\mathrm{F}-\mathrm{F}_{0}\right)=1 / \mathrm{K}_{\mathrm{a}}\left(\mathrm{F}_{\max }-\mathrm{F}_{0}\right)\left[\mathrm{Cd}^{2+}\right]^{n}+1 /\left(\mathrm{F}_{\max }-\mathrm{F}_{0}\right)$

Publisher's Note Springer Nature remains neutral with regard to jurisdictional claims in published maps and institutional affiliations.

The online version of the original article can be found at https://doi.org/ $10.1007 /$ s10895-021-02748-7

Masayori Hagimori

hagimori@mukogawa-u.ac.jp

1 Faculty of Pharmaceutical Sciences, Mukogawa Women's University, 11-68 Koshien Kyubancho, Nishinomiya 663-8179, Japan

2 Graduate School of Biomedical Sciences, Nagasaki University, 1-7-1 Sakamoto, Nagasaki 852-8501, Japan

3 Division of Medical Innovation, Translational Research Center for Medical Innovation, 1-5-4 Minatojima-minamimachi, Chuo-ku, Kobe 650-0047, Japan

4 Graduate School of Science and Engineering, Saitama University, 255 Shimo-Okubo, Sakura- ku, Saitama 338-8570, Japan

5 Graduate School of Pharmaceutical Sciences, Kyoto University, 4629 Yoshida-Shimoadachi- cho, Sakyo-ku, Kyoto 606-8501, Japan

6 Department of Biophysical Chemistry, Kobe Pharmaceutical University, 4-19-1 Motoyamakita Machi, Higashinada-Ku, Kobe 658-8558, Japan 